\title{
A Prospective Observational Study on Pregnancy Outcome in Women with Threatened Miscarriage in a Tertiary Care Centre
}

\author{
Madhurima R. ${ }^{1}$, Gigi A. ${ }^{2}$ \\ 1,2 Department of Obstetrics and Gynaecology, TDMCH, Alappuzha, Kerala, India.
}

\section{ABSTRACT}

\section{BACKGROUND}

Vaginal bleeding is prevalent in the first trimester of pregnancy and has been linked to poor pregnancy outcomes. The most common issue in the first trimester of pregnancy is threatened miscarriage. We wanted to find the pregnancy outcome and complications of threatened miscarriage.

\section{METHODS}

It is a prospective study conducted on 233 pregnant women with threatened miscarriage at Government T. D. Medical College, Alappuzha. The pregnancy outcomes and complications of threatened miscarriage such as complete miscarriage, preterm labour, preterm prelabour rupture of membrane (PPRO), preeclampsia, placental abruption, placenta previa and intrauterine foetal growth restriction (FGR), mode of delivery, low APGAR score and other foetal complications were noted. Analysis of the data was done using SPSS version 13.

\section{RESULTS}

In 233 cases there were $41(17.6 \%)$ first trimester miscarriage, 9 (3.9\%) second trimester miscarriage and $183(78.5 \%)$ pregnancies proceeded to the period of viability. Preterm births were $60(32.8 \%)$ this includes preterm premature rupture of membranes 28 (15.3\%), and term deliveries were 123 (67.2\%). Out of all women $67(36.6 \%)$ underwent Caesarean section, rest delivered vaginally. Other outcomes were foetal growth restriction 32 (17.5\%), gestational hypertension (GHTN) 26 $(14.2 \%)$, preeclampsia $14(7.7 \%)$, postpartum haemorrhage (PPH) 10 (5.5\%), manual removal of placenta (MROP) $2(1.1 \%)$, abruption $5(2.7 \%)$, and placenta previa $8(4.4 \%)$. The perinatal mortality was $1.3 \%$ due to birth asphyxia and meconium aspiration syndrome. The study showed that $17.6 \%$ ended up in first trimester miscarriage, 3.9\% ended up in second trimester miscarriage, and $78.5 \%$ proceeded to period of viability, out of whom $32.8 \%$ ended up in preterm labour, $67.2 \%$ continued till full term labour.

\section{CONCLUSIONS}

Our study has concluded that spotting or light vaginal bleeding without abdominal pain does not increase the risk of miscarriage. According to the findings of our study threatened miscarriage has several adverse maternal and foetal outcomes, which has to be explained to the mother and ensure proper follow up.

\author{
Corresponding Author: \\ Dr. Gigi A., \\ Chris Land, Kochikaran, \\ Alappuzha North P.0-688007, \\ Kerala, India. \\ E-mail: gigiantony100@gmail.com
}

DOI: $10.14260 / j e m d s / 2021 / 808$

How to Cite This Article:

Madhurima $R$, Gigi A. A prospective observational study on pregnancy outcome in women with threatened miscarriage in a tertiary care centre. J Evolution Med Dent Sci 2021;10(45):4003-4008, DOI: $10.14260 / j e m d s / 2021 / 808$

Submission 30-11-2021,

Peer Review 24-12-2021,

Acceptance 27-12-2021,

Published 31-12-2021.

Copyright (C) 2021 Madhurima R. et al. This is an open access article distributed under Creative Commons Attribution License [Attribution 4.0 International (CC BY 4.0)]

\section{KEY WORDS}

Threatened Miscarriage, Pregnancy, Outcome. 


\section{BACKGROUND}

Vaginal bleeding is commonly seen in early pregnancy, and has been accompanied with complications of pregnancy. Threatened miscarriage is the most common complication in the first trimester of pregnancy.

A history of blood-stained vaginal discharge or bleeding through closed os during the first twenty weeks of pregnancy is used to make the presumptive diagnosis of threatened abortion. ${ }^{1}$ The diagnosis is confirmed by ultrasonic evidence of an intrauterine gestational sac with cardiac activity ${ }^{1}$. Firsttrimester vaginal bleeding affects up to $25 \%$ of all pregnancies $^{1}$ and has been reported to lead to spontaneous miscarriage in $50 \%$ of affected women before foetal viability is assessed by ultrasonography.,2,3

Early pregnancy uterine bleeding poses a serious risk to the growing embryo and causes anxiety to the patient and doctor. Although few studies have evaluated outcomes other than viability at term, most agree that adverse pregnancy outcome is associated with first-trimester vaginal bleeding. ${ }^{2,4}$ The outcome of ongoing pregnancies following the first trimester bleeding is important for patients and obstetricians when planning antenatal care and clinical interventions. Even with any type of treatment either in hospital or at home, threatened miscarriage has an unpredictable prognosis. As a result, a threatened miscarriage necessitates close monitoring in order to achieve a favourable prognosis. The goal of the study is to assess the outcome of an early pregnancy with a viable foetus that has been complicated by bleed. Knowing about the increased risk associated with an early pregnancy bleed can help with management and decisions about mode, place and timing of delivery all of which will improve neonatal outcome.

Bleeding in the first trimester might come from the uterus, cervix, vaginal canal, or somewhere else. To distinguish between genital and extra-genital causes, a thorough physical examination is needed. It can be an ordinary signal of implantation of being pregnant, may be initiation of spontaneous miscarriage or can be the signal of pathological situations like ectopic pregnancy or gestational trophoblastic disease. In majority of the cases of threatened abortion the bleeding is of unknown origin and usually slight. Most of these pregnancies continue to term with or without treatment. Spontaneous abortion occurs in less than $30 \%$ of the women who experience threatened abortion. ${ }^{5}$

Subchorionic haemorrhage is a common finding in patients experiencing first trimester bleeding; in some cases, it may be associated with subsequent miscarriage. Subchorionichaematoma, occurs as a result of a rise in the placental edge or a minor sinus burst, causing elevation of the chorionic layer. In comparison to the decidua, acute haemorrhage is typically hyperechoic or isoechoic in USG.

Being in the first trimester of pregnancy, it is very common to have episodes of vaginal bleeding. But it can lead to severe complications if bleeding occurs in the second or third trimester of pregnancy. Around $50 \%$ of pregnancies end in abortion; if pregnancy continues it can lead to preterm delivery, preterm prelabour rupture of membrane, preeclampsia, placental abruption and intrauterine growth restriction (IUGR).

\section{Objectives}

Current study is mainly to emphasize the significance of early detection and treatment in improving maternal and perinatal outcomes. To highlight the necessity of antenatal registration and admission, which is required for better and more effective obstetric care. To determine the percentage of pregnant women who experience vaginal bleeding in the early pregnancy and experience first trimester miscarriage, second trimester miscarriage, preterm labour, or full-term labour. To determine the value of current obstetric care in the management of early pregnancy vaginal bleeding.

To find out the pregnancy outcome and complications of threatened miscarriage such as complete miscarriage, preterm labour, premature rupture of membrane, preterm prelabour rupture of membrane, preeclampsia, placental abruption, placenta previa and intrauterine foetal growth restriction, low APGAR score or any other complications.

\section{METHODS}

This prospective observational study was done after Institutional Ethical Committee approval was obtained and informed consent taken from patients who met inclusion criteria.

\section{Sample Size}

Calculated by the formula $\mathrm{n}=4 \mathrm{pq} / \mathrm{d}^{2}$

According to previous study prevalence is 30 , so sample size derived is 233 .

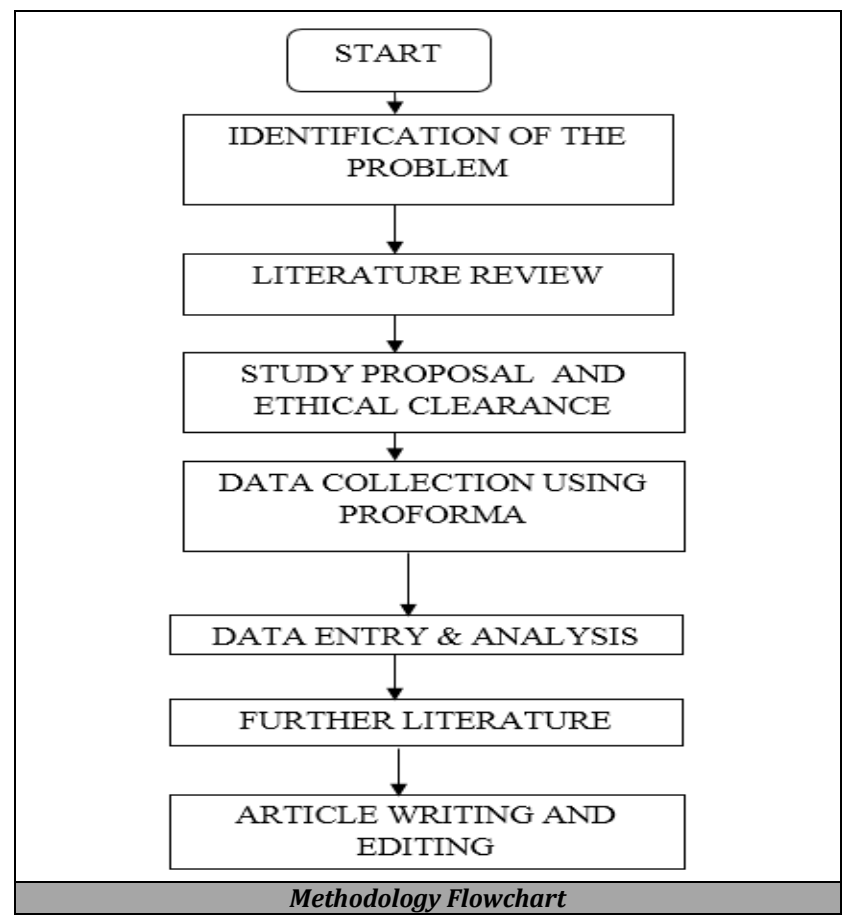

Pregnant women with vaginal bleeding, with or without abdominal discomfort, and a closed cervical os with an ultrasonographic confirmed live foetus, up to 20 weeks of gestation were included. Those with a known bleeding disorder and a local cause of bleeding identified by speculum examination were eliminated. All of the patients in the study were admitted to the hospital. A comprehensive history, 
including age, socioeconomic situation, amount of bleeding, gestational age, and previous pregnancies was taken after hospitalisation.

After obtaining history, to rule out ectopic pregnancy, an abdominal examination was performed to assess the uterine size and look for signs of intraperitoneal haemorrhage such as tenderness, free fluid, guarding and rigidity. Local causes were excluded by local examination of external genitalia and per speculum. Bimanual pelvic examination was performed to measure the uterus size, consistency, and presence or absence of forniceal and cervical motion tenderness. Basic investigations such as haemoglobin, routine and microscopic examination of urine, thyroid stimulating hormone (TSH), 75 grams glucose tolerance test (GTT), blood group, and Rh type were performed after the clinical assessment. All patients underwent ultrasonography to confirm intrauterine pregnancy, determine the gestational age, confirm foetal cardiac activity, locate the placenta and identify subchorionic hematoma.

Patients were advised bed rest during their hospital stay. They were not given any medications or hormones. These patients were followed up on until delivery or abortion. The participants were followed up monthly until 28 weeks, two weeks between $28 \& 36$ weeks and there after weekly. During antenatal check-ups maternal complications like spontaneous abortion, gestational hypertension, preeclampsia, eclampsia, placenta previa, placental abruption, preterm premature rupture of membranes, premature rupture of membrane, preterm labour, malpresentation, foetal complications were looked for and managed. Intrapartum information such as gestational age at delivery, delivery mode, third stage complications like retained placenta, postpartum haemorrhage were noted. After delivery APGAR score was calculated and recorded, neonatal complications were noted.

\section{Statistical Analysis}

All data was entered in Microsoft Excel sheet and analysed using SPSS statistical software. Frequency and percentage were used to describe the variables.

\section{RESULTS}

From our study it can be concluded that the bleeding in the first trimester was more common in primigravida during 9 to 12 weeks of gestation who are in the age group of 20 to 24 years. There is no effect on perinatal outcome when the patient reached term.

In 233 cases there were 41 (17.6\%) first trimester miscarriage, 9 (3.9\%) second trimester miscarriage and 183 (78.5\%) pregnancies proceeded to the period of viability. Out of 183 cases with continued pregnancy, 60 (32.8\%) were preterm cases. This also includes PPROM 28(15.3\%). Remaining cases 123 (67.2\%) were term deliveries. Out of 183 cases, 67 (36.6\%) underwent Caesarean section, rest 116 (63.4\%) delivered vaginally. Pregnancy outcomes were FGR 32 (17.5\%), GHTN 26 (14.2\%), preeclampsia 14 (7.7\%), abruption 5 (2.7\%), placenta previa 8 (4.4\%). Delivery complications were PPH 10 (5.5\%), MROP 2 (1.1\%), and Caesarean delivery 67 (36.6\%). There was total $3(1.3 \%)$ perinatal mortality because of birth asphyxia and they were preterm deliveries < 32 weeks. APGAR of the babies were dependent on various factors like prematurity, birth asphyxia, meconium aspiration syndrome (MAS).

Thus, the study showed that $17.6 \%$ ended up in first trimester miscarriage, $3.9 \%$ ended up in second trimester miscarriage, and $78.5 \%$ proceeded to period of viability of whom $32.8 \%$ ended up in preterm labour, $67.2 \%$ ended up in full term labour.

\begin{tabular}{|ccc|}
\hline Pregnancy Outcome & Frequency & Percentage \\
Miscarriage & 50 & $21.5 \%$ \\
Pregnancy continued & 183 & $78.5 \%$ \\
Total & $\mathbf{2 3 3}$ & $\mathbf{1 0 0} \%$ \\
\hline & Pregnancy Outcome \\
\hline
\end{tabular}

\begin{tabular}{|ccc|}
\hline Pregnancy Complications & Frequency & Percentage \\
GHTN & 26 & $14.2 \%$ \\
Preeclampsia & 14 & $7.7 \%$ \\
Eclampsia & 0 & $0 \%$ \\
FGR & 32 & $17.5 \%$ \\
Abruption & 5 & $2.7 \%$ \\
Placenta previa & 8 & $4.4 \%$ \\
\hline & Pregnancy Complications \\
\hline
\end{tabular}

\begin{tabular}{|ccc|}
\hline Delivery Complications & Frequency & Percentage \\
Preterm labour & 60 & $32.8 \%$ \\
PPROM & 28 & $15.3 \%$ \\
Caesarean delivery & 67 & $36.6 \%$ \\
PPH & 10 & $5.5 \%$ \\
MROP & 2 & $1.1 \%$ \\
\hline \multicolumn{2}{c}{} \\
\hline
\end{tabular}

\begin{tabular}{|ccc|}
\hline Mode of Delivery & Frequency & Percentage \\
Spontaneous & 82 & $44.8 \%$ \\
Induced vaginal & 34 & $18.6 \%$ \\
Caesarean & 67 & $36.6 \%$ \\
Total & $\mathbf{1 8 3}$ & $\mathbf{1 0 0} \%$ \\
\hline \multicolumn{3}{c}{} \\
\hline
\end{tabular}

\begin{tabular}{|ccc|}
\hline Perinatal Outcome & Frequency & Percentage \\
Low birthweight & 70 & $38.3 \%$ \\
Babies delivered <37 weeks & 60 & $32.8 \%$ \\
AGPAR < 7 at 1 minute & 20 & $11.2 \%$ \\
NICU admission & 21 & $11.8 \%$ \\
Resuscitation & 10 & $5.6 \%$ \\
Early neonatal death & 3 & $1.6 \%$ \\
\hline \multicolumn{3}{c}{} \\
\hline
\end{tabular}

\section{DISCUSSION}

Vaginal bleeding is frequent during pregnancy, especially in the first trimester, and can be caused by blood vessels disruption in the decidua or from cervical, vaginal, or uterine pathology. First-trimester vaginal bleeding affects up to $25 \%$ of all pregnancies and has been reported to lead to spontaneous miscarriage in $50 \%$ of affected women before foetal viability is assessed by ultrasonography. Those who continue the pregnancy experience an increased risk of subsequent complications.

In this study, majority of the participants are in the age group of 20-24 years (36.1\%) followed by 25-29 years (27.9\%), 30-34 years (23.6\%), $\geq 35$ (7.3\%), <20 (5.2\%) and mean maternal age was 28.4 years. The results were comparable with other studies, according to Batzofin et al. ${ }^{6}$ mean maternal age was 29.5 years. In a review investigation of 516 patients with first-trimester bleeding, according to Bennett et al. ${ }^{7}$ overall pregnancy loss rate was $9.3 \%$. Pregnancy loss increases with advanced maternal age and early gestational age. The rate was $13.8 \%$ in women with age 
more than 35 years and $7.3 \%$ in women less than 35 years. For those bleeding at or before 2 months, it was $13.9 \%$ and $5.9 \%$ for those bleeding later in gestation.

On the basis of Yang analysis, 25\% of women have experienced bleeding, with the occurrence peaking during the first month of pregnancy. ${ }^{8}$

The study group in the Harvelle study had bleeding at 8 weeks of pregnancy and the study was constrained by small number of participants and focused on premature birth. Both these studies exclude the miscarriage. ${ }^{9}$

In Axelsen study, ${ }^{10}$ the study group had bleeding at 8 weeks and associates this with miscarriage and preterm birth.

In our study the mean gestational age at the time of bleeding was 11 weeks. Around $80.3 \%$ had bleeding <14 weeks and $19.7 \%$ had bleeding $\geq 14$ weeks. The results were comparable with Dongol et al. study where mean gestational age at the time of bleeding was 12 weeks.

In our study around $57.5 \%$ of the study participants were primigravida followed by $42.5 \%$ were multi gravida. The results were comparable with Dongol et al. study results, with $45.7 \%$ primigravida and $54.3 \%$ multi gravida.

A cohort and case control study done by Methodius suggested that there is a relation connecting $\mathrm{SCH}$ with increased risk of early and late pregnancy loss, abruption, preterm labour and PROM.11 Whereas in our study almost 27 patients (24.9\%) had SCH in USG. Among this $6(22 \%)$ ended with first trimester abortion, 3 (11\%) with second trimester abortion, 3 (11\%) with preterm labour and 15 (55\%) with full term labour. According to chi-square test, $p<0.05$, so there is statistically significant association between pregnancy outcome and USG finding of sub chorionic miscarriage. So, cases with SCH in USG are associated with threatened abortion. Geniviene L Bennet investigated the effects of SCH and found that when SCH happened less than 8 weeks after conception the rate of spontaneous abortion was higher. ${ }^{12}$

Out of 233 study participants only $15 \%$ had medical illness. Among them majority were suffering from diabetes mellitus $(6.0 \%)$ followed by $5.2 \%$ thyroid disorder, $1.3 \%$ systemic hypertension, $0.9 \%$ heart disease, bronchial asthma respectively, and $0.4 \%$ had anaemia related complications. Around $21.5 \%$ of the study participants had history of various infections before bleeding, like urinary tract infection and vaginitis. In our study according to chi-square test, $\mathrm{p}<0.05$, so there is statistically significant association between pregnancy outcome and history of infections. So, there is significant association between history of infection and threatened abortion.

With respect to pregnancy outcome, in our study overall $78.5 \%$ of the study participants continued their pregnancy and $21.5 \%$ had miscarriage. The results were comparable with Rashmi et al. ${ }^{13}$ study where total of $88 \%$ of the study participants continued the pregnancy and only $12 \%$ had abortions.

With respect to pregnancy complications, in our study out of all study participants, $17.5 \%$ had FGR, $14.2 \%$ had gestational hypertension, $7.7 \%$ preeclampsia, $4.4 \%$ placenta previa and $2.7 \%$ had abruption. Our results were comparable with Weiss et al. ${ }^{14}$ study where $11.2 \%$ had gestational hypertension, $6.3 \%$ had preeclampsia, $4.3 \%$ had FGR, $4 \%$ abruption, $2.2 \%$ had placenta previa.
Regarding delivery complications, in our study out of all the study participants $36.6 \%$ had Caesarean delivery, $32.8 \%$ had preterm labour including 15.3\% PPROM, 5.5\% had PPH and $1.1 \%$ had MROP. Bleeding during first trimester was related with expanded danger of preterm delivery. Both Batzofin and Williams found that preterm delivery risk was doubled in patients with bleeding when compared to patients without bleed. Because of impaired implantation spontaneous abortion may happen in early pregnancy while preterm delivery, PPROM, placental abruption and preeclampsia may occur in later period. Our outcomes were like those announced before by Hossain et al. ${ }^{15}$ Because of expanded free iron stores from subchorionic bleeding, hydroxyl radical is catalysed damaging the layers prompting unconstrained premature births like Edwards et al. study. In Saraswat et al. ${ }^{16}$ study comparative outcomes were shown for PPROM.

It's hypothesized that the adjacent haemorrhage disrupted the chorio-amniotic plane, making the membranes more vulnerable to rupture. Alternatively, the presence of blood for an extended period of time may serve as a nidus for intrauterine infection. Subclinical uterine contractions may be triggered by persistent or repeated placental bleeding, resulting in cervical alteration and, eventually, ruptured membranes. Other studies have found a twofold increase in the rate of preterm birth among women who had threatened miscarriage. ${ }^{17,18,19}$

According to several studies, bleeding in the first trimester of pregnancy is frequently linked with bleeding in the second and third trimesters as well. This is due to the possibility of placental disruption, placenta previa, and unknown origin bleeding. 16,20 The frequency of early rupture of membranes is 2 to 4 times higher with 1 st trimester bleeding, according to the same studies. ${ }^{20}$

Yang et al. studied the relationship between preterm births and self-reported vaginal bleeding in 2829 women, and found that there was a minor link between first trimester vaginal bleeding and premature labour (risk ratio was 1.3). Early preterm birth, which is birth before 34 weeks, was largely linked to threatened abortion, with premature rupture of membranes being the most common cause of preterm labour. Preterm birth, PPROM, and preterm labour were all linked to recurrent bleeding for more than 26 days with a higher amount.

In a retrospective study, Wijesiriwardana et al. ${ }^{18}$ found that antepartum haemorrhage affected $15.5 \%$ of patients with threatened miscarriage and $9.1 \%$ of controls. Das et al. ${ }^{21}$ observed a higher rate of placenta previa among patients with heavy bleeding per vagina during the first trimester. Placenta previa was more common, but not significantly so, in the pregnant women with threatened miscarriage. According to Hertz JB Heisenberg, placental retention was connected to a risk of abortion and necessitated manual removal of the placenta at a rate of $14 \%$. They theorised that adhesive scarring between uterine wall and the placenta at the site of bleeding was to blame for the increased incidence of placental retention in women who were on the verge of abortion.

Out of 183 study participants who continued pregnancy in our study, $44.8 \%$ had spontaneous delivery, $36.6 \%$ had Caesarean section and $18.6 \%$ had induced vaginal delivery. The results were comparable with Das et al. according to this 
study, spontaneous delivery was $56.36 \%$, induced vaginal delivery was $20 \%$, Caesarean delivery was $14.5 \%$. Although Joshua et al. ${ }^{17}$ found no link between threatened miscarriage and increased Caesarean delivery, Wijesiriwardana et al. identified a greater rate of elective Caesarean delivery among threatened miscarriage patients due to placenta previa and other factors like malpresentations.

Birth weight of the babies compared with various studies, out of 183 study participants who continued pregnancy $36.1 \%$ had delivered babies of $2.5-3 \mathrm{~kg}$ birth weight, $31.7 \%$ delivered babies of 1.5-2.5 kg birth weight, $25.7 \%$ had delivered babies of more than $3 \mathrm{~kg}$ birth weight and, $3.3 \%$ had delivered babies of less than $1 \mathrm{~kg}$ birth weight, mean birth weight was $2.67 \mathrm{~kg}$. According to Wijesiriwardana et al. mean birth weight was $2.34 \mathrm{~kg}$.

Perinatal outcome was also compared with other studies. In our study the perinatal outcomes of low APGAR score (APGAR score $<7$ ), $11.2 \%$ of babies had low APGAR score. This finding was consistent with numerous other research that found a link between an APGAR score of less than 7 and vaginal bleeding in the first trimester. A similar study by William et al. ${ }^{19}$ indicated that delivering a preterm new born with foetal distress and a low APGAR score had a 2.5 -fold increase in the chance of neonatal mortality as well as a 2.5fold increase in the risk of neonatal death in women with threatened abortion.

Since the rate of pre term delivery was more in these women the rate of neonatal intensive care admission was also high in these women. In our study the rate of NICU admission was $11.8 \%$. Low birth weight (less than 2500 g) was shown to be more common in pregnancies affected by vaginal bleeding, according to Haddow et al.

\section{CONCLUSIONS}

Threatened abortion has no specific treatment. All patients need appropriate counselling. Patients are offered ongoing support, sympathetic approach, and follow-up care. This involves a careful explanation of the pathophysiology. Our study has concluded that spotting or light vaginal bleeding without abdominal pain does not increase the risk of miscarriage. According to the findings of our study threatened miscarriage has several adverse maternal and foetal outcomes, which has to be explained and ensure proper follow up.

Data sharing statement provided by the authors is available with the full text of this article at jemds.com.

Financial or other competing interests: None.

Disclosure forms provided by the authors are available with the full text of this article at jemds.com.

\section{REFERENCES}

[1] Cunningham FG, Gant NF, Leveno KJ, et al, editors. William's obstetrics. 25th edn. New York (NY): McGrawHill 2018:348-9.
[2] Farrell T, Owen P. The significance of extrachorionic membrane separation in threatened miscarriage. $\mathrm{Br} \mathrm{J}$ Obstet Gynaecol 1996;103(9):926-8.

[3] Chung TK, Sahota DS, Lau TK, et al. Threatened abortion: prediction of viability based on signs and symptoms. Aust N Z J Obstet Gynaecol 1999;39(4):443-7.

[4] Verma SK, Premi HK, Gupta TV, et al. Perinatal outcome of pregnancies complicated by threatened abortion. J Indian Med Assoc 1994;92(11):364-5.

[5] Dongol A, Mool S, Tiwari P, et al. Outcome of pregnancy complicated by threatened abortion. Kathmandu Univ Med J (KUMJ) 2011;9(33):41-4.

[6] Batzofin JH, Fielding WL, Friedman EA. Effect of vaginal bleeding in early pregnancy on outcome. Obstetrics \& Gynecology 1984;63(4):515-8.

[7] Bennett GL, Bromley B, Lieberman E, et al. Subchorionic hemorrhage in first-trimester pregnancies: prediction of pregnancy outcome with sonography. Radiology 1996;200(3):803-6.

[8] Yang J, Savitz DA, Dole N et al. Predictors of vaginal bleeding during the first two trimesters of pregnancy. Paediatr Perinat Epidemiol 2005;19(4):276-83.

[9] Harville EW, Wilcox AJ, Baird DD, et al. Vaginal bleeding in very early pregnancy. Hum Reprod 2003;18(9):19447.

[10] Axelsen SM, Henriksen TB, Hedegaard M, et al. Characteristics of vaginal bleeding during pregnancy. Eur J Obstet Gynecol Reprod Biol 1995;63(2):131-4.

[11] Tuuli MG, Norman SM, Odibo AO, et al. Perinatal outcomes in women with subchorionic hematoma: a systematic review and meta-analysis. Obstet Gynecol 2011;117(5):1205-12.

[12] Bennett GL, et al. Subchorionic hemorrhage in first trimester pregnancies: prediction of pregnancy outcome with sonography. In: Seeds JW, Chescheir NC, Wade RV, ed. Practical sonography in obstetrics and gynecology. 2nd edn. Philadelphia: Lippincott-Raven Pulishers 1996.

[13] Rashmi K. Anitha GS, Radhika. Prospective study of pregnancy outcome in patients with first trimester bleed in tertiary centre. International Journal of Clinical Obstetrics and Gynaecology 2020;4(3):22-5.

[14] Weiss JL, Malone FD, Vidaver J, et al. Threatened abortion: a risk factor for poor pregnancy outcome, a population-based screening study. Am J Obstet Gynecol 2004;190(3):745-50.

[15] Hossain R, Harris T, Lohsoonthorn V, et al. Risk of preterm delivery in relation to vaginal bleeding in early pregnancy. Eur J Obstet Gynecol Reprod Bio 2007;135(2):158-63.

[16] Saraswat L, Bhattacharya S, Maheshwari A, et al. Maternal and perinatal outcome in women with threatened miscarriage in the first trimester: a systematic review. BJOG 2010;117(3):245-57.

[17] Weiss JL, Malone FD, Vidaver J, et al. Threatened abortion: a risk factor for poor pregnancy outcome, a population based screening study. Am J Obstet Gynecol 2004;190(3):745-50.

[18] Wijesiriwardhana A, Bhattacharya S, Shetty A, et al. Obstetric outcome in women with threatened miscarriage in the first trimester. Obstet Gynaecol 2006;107(3):557-62. 
[19] Williams MA, Mittendorf R, Leiberman E, et al. Adverse infant outcome associated with first trimester vaginal bleeding. Obstet Gynecol 1991;78(1):14-8.

[20] Siddiqui F, Kean L. Intrauterine fetal death. Obstetrics, Gynaecology and Reproductive Medicine 2009;19(1):1-6
[21] Das AG, Gopalan S, Dhahwal LK. Fetal growth and perinatal outcome of pregnancies continuing after threatened abortion. Aust N Z J Obstet Gynaecol 1996;36(2):135-9. 